\title{
A PRACTICAL METHOD FOR PLANNING LARGE NUMBER OF HORIZONTAL WELLS WITH A RESERVOIR MODEL FOR A FIELD DEVELOPMENT PLAN
}

\author{
Guido Fava', Dinh Viet Anh' \\ 'Schlumberger \\ 2Petrovietnam Exploration Production Corporation \\ Email: anhdv@pvep.com.vn \\ https://doi.org/10.47800/PVJ.2021.10-02
}

\section{Summary}

The most advanced technique to evaluate different solutions proposed for a field development plan consists of building a numerical model to simulate the production performance of each alternative. Fields covering hundreds of square kilometres frequently require a large number of wells. There are studies and software concerning optimal planning of vertical wells for the development of a field. However, only few studies cover planning of a large number of horizontal wells seeking full population on a regular pattern.

One of the criteria for horizontal well planning is selecting the well positions that have the best reservoir properties and certain standoffs from oil/water contact. The wells are then ranked according to their performances. Other criteria include the geometry and spacing of the wells. Placing hundreds of well individually according to these criteria is highly time consuming and can become impossible under time restraints. A method for planning a large number of horizontal wells in a regular pattern in a simulation model significantly reduces the time required for a reservoir production forecast using simulation software. The proposed method is implemented by a computer script and takes into account not only the aforementioned criteria, but also new well requirements concerning existing wells, development area boundaries, and reservoir geological structure features.

Some of the conclusions drawn from a study on this method are (1) the new method saves a significant amount of working hours and avoids human errors, especially when many development scenarios need to be considered; (2) a large reservoir with hundreds of wells may have infinite possible solutions, and this approach has the aim of giving the most significant one; and (3) a horizontal well planning module would be a useful tool for commercial simulation software to ease engineers' tasks.

Key words: Asset and portfolio management, field development optimisation and planning, water saturation, reservoir simulation, directional drilling.

\section{Introduction}

The designs of development plans for oil and gas fields are based on the definition of a drilling schedule. Development wells are drilled to (a) reach and support a production plateau; (b) maximise the hydrocarbon recovery; and (c) provide injection for pressure support or secondary recovery.

Date of receipt: 30/9/2021. Date of review and editing: 30/9 - 7/10/2021 Date of approval: 7/10/2021.

This article was presented at SPE Kuwait Oil and Gas Show and Conference and licensed by SPE (License ID: SPE-175169-MS) to the republish full paper in Petrovietnam Journal.
The task addressed in this work is a full population of the field with as many horizontal wells as needed to get the maximum possible production rate and optimal desired production that is maintained for several years. This study should be distinguished from other studies available in the literature that are focused on production optimisation with a minimum number of well locations yielding a high recovery per well. The well population in this work is based on a regular pattern rather than selection of optimal random locations. The evaluation of every possible location on a regular pattern was found to be a frequent request from field operators because it suits their local and economic circumstances. Interference be- 
tween wells is implied in such conditions. Every location needs to be filtered against several restrictions, and the optimal vertical planning of the horizontal section needs to be defined. Doing this task individually for hundreds of wells is highly time consuming, thus unpractical, and can become impossible under time restraints.

This problem is solved by developing a programme that automates the subject task, issuing the simulator keywords with all the items needed for the section of a simulator data file referring to new wells position and production. In this study, a commercial black oil reservoir simulation software was used.

The next variable to be defined is the schedule on which each well is to be drilled. The programme contributes to this task by issuing a drilling queue. The output of the programme is but a starting point from which many locations will be depurated, and the drilling schedule may be optimised in subsequent simulation runs.

\section{Literature review}

There are a few software packages that can provide new well locations for field development plan. The best approach is performed by the Plan Opt module in the simulator. However, this application is specific for vertical wells. A guided decision software is another option, but it specifies not being accurate for horizontal wells.

There are a number of studies concerning finding well locations. These studies focus on a different goal though, which is to optimise the number of wells by carefully selecting the best locations. Hazlett and Babu [1] provide an analytic solution of Babu and Odeh [2] for horizontal well productivity that is used together with a search method to find optimal well locations. The solution of Babu and Odeh for horizontal wells in a box of homogeneous properties is generalised for heterogeneous media. This equation is useful for the computation of productivity index.

Cullick et al. [3] present a process for simultaneously determining many optimal locations for producing and injecting wells. The optimisation is performed by a software system that executes the reservoir simulator, an economic analysis, and the optimiser. A set of well targets is generated on a conventional reservoir model by ranking its properties.

In a study by Cottini-Loureiro and Araujo, the optimal well location is achieved by combining the methods of multiple realisation approach and quality map [4]. The multiple realisation approach is based on identifying key parameters of the reservoir and modelling of the reservoir response for a combination of parameters. The quality map is a $2 D$ representation of the quality of all the area of the reservoir in terms of production. It is generated by running a flow simulator multiple times, varying the position of a single well in each run until the entire grid is covered.

None of the papers found in the literature refers to a regular pattern development, which has been frequently requested by field operators because it is suitable for local and economic circumstances. Another issue is that previous studies generally propose the use of software that is not readily available.

\section{Methodology}

A step-by-step procedure of the proposed technique follows.

\subsection{Oil column index map}

The first criterion used to evaluate the well location spatially is the areal oil in place, volume of oil in place per unit surface, oil column index, or the $\mathrm{H}_{\mathrm{u}} \times \Phi \times \mathrm{S}_{\mathrm{o}}$ quantity. This number can be expressed in units of thickness or commonly in Rbo/acre through a conversion factor of $1 \mathrm{ft}$ $=7757.4630 \mathrm{Rbo} /$ acre.

There are several ways of evaluating this quantity depending on the software used for the geological model. In the example case, a script was written to calculate a map of $\mathrm{H}_{\mathrm{u}} \times \Phi \times \mathrm{S}_{\mathrm{o}}$ from the files of the simulation model because the geological model was not provided.

An oil column index map provides a view of the density of oil accumulation over all the area of the field. Best areas can be easily spotted so as to locate vertical or horizontal wells assuming that the vertical permeability is good enough to drain each sector of the field with a single horizontal branch.

In the case that the reservoir is divided totally or partially in the vertical direction by horizontal intercalations or barriers, $\mathrm{H}_{\mathrm{u}} \times \Phi \times \mathrm{S}_{\mathrm{o}}$ needs to be calculated for each division. Also, each of those divisions will be processed by the well location programme.

\subsection{Programme input and output}

The developed programme locates as many horizontal wells as possible in a field, on the basis of a regular rect- 
angular pattern. The total oil in place for the drainage area of each location is added and compared with a minimum value. Locations under the minimum mean theoretically nonproductive wells and are discarded, together with those falling in restricted areas and other obstacles. Finding the maximum possible number of wells has the objective of achieving the maximum production and supporting it during a number of years.

Within each location, the well position is vertically optimised, i.e., the well will be connected to the layer that gives the higher productivity index and respects a minimum standoff from the water level.

As every potential location is covered with the regular pattern, the additional information provided by the programme is the order in which the wells will be drilled. The input and output are referred to the commercial simulator model.

- Input data

+ Grid dimensions;

+ Grid file (geometry);

+ Properties;

+ Sizes of rectangular pattern (drainage area);

+ Length of horizontal well;

+ Orientation of the wells $(\mathrm{X}$ or $\mathrm{Y})$;

+ Co-ordinates I, J, K of existing well connections;

+ Co-ordinates I, J, K of obstacles or forbidden locations;

+ Co-ordinates I, J, K of development area;

+ Map of Rbo/acre (bi dimensional grid).

Keywords are those corresponding to the specific simulator.

The dimensions of the rectangular pattern are usually established based on the field operator's policy on minimum spacing and drainage area. If this is not the case, an initial value can be given by experience in similar fields. The length of the horizontal well is a matter of drilling feasibility.

The orientation of the wells, along the $\mathrm{X}$ or $\mathrm{Y}$ axis in this programme, is a parameter that has to be chosen according to the main flow direction of the reservoir. In isotropic reservoirs, it will be a sensitivity parameter. Sensitivity can also be run on drainage area and horizontal length.

\section{- Output data}

This information is for new wells in a format suitable for the reservoir simulation software's Schedule section:

+ Wellhead specification;

+ Well connections;

+ Well production control;

+ Drilling order.

Keywords are those corresponding to the specific simulator.

\subsection{Processing the results}

Once the output of the programme is obtained, the keywords are added to the Schedule section of the model, and a forecast is run. A field or group target is imposed.

The new wells are all closed in the well completion data keyword, and they will be opened to production as soon as the field cannot meet its target in the order they are listed on the drilling queue list. The main results of such run are:

- Achievement of target rate;

- Duration of production plateau;

- Increment of oil cumulative for the field in the forecasted period;

- Number of wells with effective production.

\subsection{Result evaluation}

The conditions for which the wells were located in the original pattern may have changed by the moment many of them are opened because of the water influx and other fluid movement. The arrays $\mathrm{S}_{\mathrm{w}}$ and $\mathrm{H}_{\mathrm{u}} \times \Phi \times \mathrm{S}_{\mathrm{o}}$ can be calculated at a later time (i.e., when the main regions of the reservoir are flooded), and the programme will be run again.

In this case, besides using the mentioned arrays as input, the new located wells that are considered good in Step 3 are included in the existing well list. The purpose of this additional run is to correct the vertical location of wells that can perform better if drilled higher at later time.

This step may not be necessary in fields where saturation change is not important. On the other extreme, this step can be performed more than once. 


\subsection{Test runs}

Repeating Step 3 with a smaller number of wells can significantly modify the production of the wells that are kept. Successive runs of Step 3, and eventually Step 4, will define which wells are required to achieve the targets for field development.

\subsection{Application and report}

The wells defined in Step 5 can be used for forecasts at lower plateau targets, usually supporting the plateau production longer time.

\section{Computer programme}

The aim of the developed programme is to fully populate a field with horizontal wells following a regular rectangular pattern.

A defined surface of the field is totally covered, with exception of locations that fall into:

- Existing wells;

- Non-productive areas;

- Obstacles such as faults;

- Areas restricted by administrative or other reasons.

This programme can be repeated with several alternatives, e.g. well orientation ( $\mathrm{X}$ or $\mathrm{Y}$ ), spacing, and horizontal length. From each output, a forecast can be run to find the maximum production and support it during a number of years.

It is not the objective of the programme to give the optimal solution for developing the field. As mentioned in the previous section, that solution can be found only by loading several alternative outputs from the programme into the simulation model and comparing the results.

The programme described is aimed and restricted to use with the referred commercial software grid and solution files as input. Also, the output from the programme consists of files that can directly be included in the Schedule section of the reservoir simulation software's data file. However, it is expected that the programme can be modified to be used for other reservoir simulators as well.

\subsection{Programme input}

The version of the programme that is ready to use has been developed for application on a specific field with a single characteristic: high-permeability channels driving water.
The user will prepare a text file containing the following information in free format. This file is called the well input file. An example of the well input file is provided in the Appendix. The data contained in that file are, line by line:

- I, J, K dimensions;

- Character string to fill each well completion data line after the $\mathrm{K}$ connections;

- Character string to fill each well production control line after the name of the well;

- Maximum and minimum I coordinates of development area; maximum and minimum $J$ coordinates of development area; I and J sizes of rectangular drainage area; horizontal length; orientation code: $0=X, 1=Y$;

- Characters of well name and initial number for wells;

- Character string to fill each WELSPECS line after the well coordinates.

From 7 to $\left(I_{\max }-I_{\min }+7\right)$ is $J_{\min }(I), J_{\max }(I)$. These lines define the area where the wells are allowed. The next lines are I, J coordinates of connections of existing wells and other obstacles.

Other files required as input are:

- Permeability input file contains the array as extracted from the grid file of the commercial simulator, which is an input of the reservoir model (this input is specific for this version of the programme, and is used to avoid locating wells in the high-permeability channels);

- Z co-ordinates file contains the array as extracted from the grid file of commercial simulator, which is an input for the reservoir model (this specific array specifies the depths for each one of eight corners of each cell in the model);

- Connate water saturation input file contains an array of connate water saturation; it can be exported from a postprocessor module once the reservoir model is initialised;

- Current water saturation input file contains an array of water saturation at the start time for the forecast; it can be exported from the postprocessor module once the reservoir model has been run to the end;

- Transmissibility data in $X$ and $Y$ directions contains an array of horizontal transmissibility in the direction normal to well orientation; it can be exported from the postprocessor module once the reservoir model is 
initialised (this input is specific for this version of the programme, which assumes that the wells having the highest normal transmissibility will have the highest productivity index);

- Oil column index data-contains a 2D $(I, J)$ array of the variable oil column index $=\mathrm{H}_{\mathrm{u}} \times \Phi \times \mathrm{S}_{\mathrm{o}}$ in Rbo/acre; this variable has been calculated by multiplying the porosity $(\Phi)$ of each cell by its net thickness $\left(H_{u}\right)$ and its oil saturation $\left(S_{0}\right)$, and for each I and $J$, the value of $H_{u} \times \Phi \times$ $\mathrm{S}_{\mathrm{o}}$ for each cell has been added for all the column from $\mathrm{K}=$ 1 to $\mathrm{K}$ maximum (this can be made by means of a script in the postprocessor module or using a Fortran programme).

With all data files in the run directory, the programme can be run by opening the command window, positioning in the run directory, and typing HorWS, which is the name of the programme.

\subsection{Programme workflow}

The programme starts by reading the dimensions I, J, $\mathrm{K}$ of the model to allocate the input arrays. Once the arrays have the correspondent dimensions, the input files are read. The mobile water saturation for each cell is calculated as the difference between actual water saturation $\left(\mathrm{S}_{\text {wat }}\right)$ and critical water saturation $\left(\mathrm{S}_{\text {wrr }}\right)$. The location of the well inside each rectangular area of the pattern is defined symmetrically based on the sizes of area, well length, and orientation. As mentioned above, this version of the programme looks for the high-permeability channels, of approximately $100 \mathrm{D}$, connecting the aquifer with the crest of the reservoir. Such channels consist of cells where permeability is greater than or equal to $100 \mathrm{D}$ and where this value is constant vertically from $K=1$ to $K$ maximum. Cells in this condition are detected, so wells are avoided on these channels and at a distance of 5 cells from them. In a more general version, this definition can be made outside the programme. Then, the co-ordinates of the channel cells can be included in the list of obstacles where drilling is forbidden.

The regular pattern is covered starting from the corner of the development area having the lowest I and $\mathrm{J}$ coordinates and proceeding along the $J$ axis. Each location is filtered from obstacles (e.g. wells and channels). If there is an old well in the rectangular area of the location, then the programme goes to the next location. The summation of the oil column index is made for all the cells connected to the well; if it is zero, the location is discarded. This value will be used to classify the wells according to the potential oil they can recover. To define the depth to drill the horizontal section of the well, the first criterion is to keep a standoff above mobile water. Starting from the uppermost layer and along the well length, the mobile water saturation is compared to a reference value of 0.15 . All layers below the one having mobile water saturation greater than or equal to the reference are discarded for completion, plus two layers as a standoff from water level. This is under the assumption that mobile water saturation will increase monotonically downwards. From the uppermost layer filtered as described above up to Layer 1, the normal transmissibilities are added along the well length. Then, the well is completed in the layer having the highest transmissibility summation, as it is assumed that it will correspond to the highest productivity index. Note that the well is completed in a single layer, which can depart from horizontality. A minimum value of oil column index greater than zero can be used to the filter the locations based on a statistical analysis of the Rbo/acre map.

\subsection{Programme output}

All the wells that pass the filters are recorded in three output files:

- Well specification file which contains the specifications for each new well;

- Completion data file which contains the well completion specification for every connection of new wells;

- Well control file which contains the well production control standard specifications for each new well; the wells are specified as shut, and they will be opened automatically to attain the production targets by using the drilling queue keyword that is added to the file as described below.

A subroutine is used to assign, from the array of corner $Z$ co-ordinates, the eight corners corresponding to each connected cell. The corresponding depths are averaged, and the deepest connection is selected as representative for each well. At this point, every potential location is covered with the regular pattern. The next step is to classify the wells to assign the order in which each will be opened. The first criterion is that the lowest wells will be produced earlier so as not to leave oil behind the advancing water.

Another subroutine called ORDEM sorts the wells by their representative depth in descending order. This sorting is done by assigning to each well an order number 


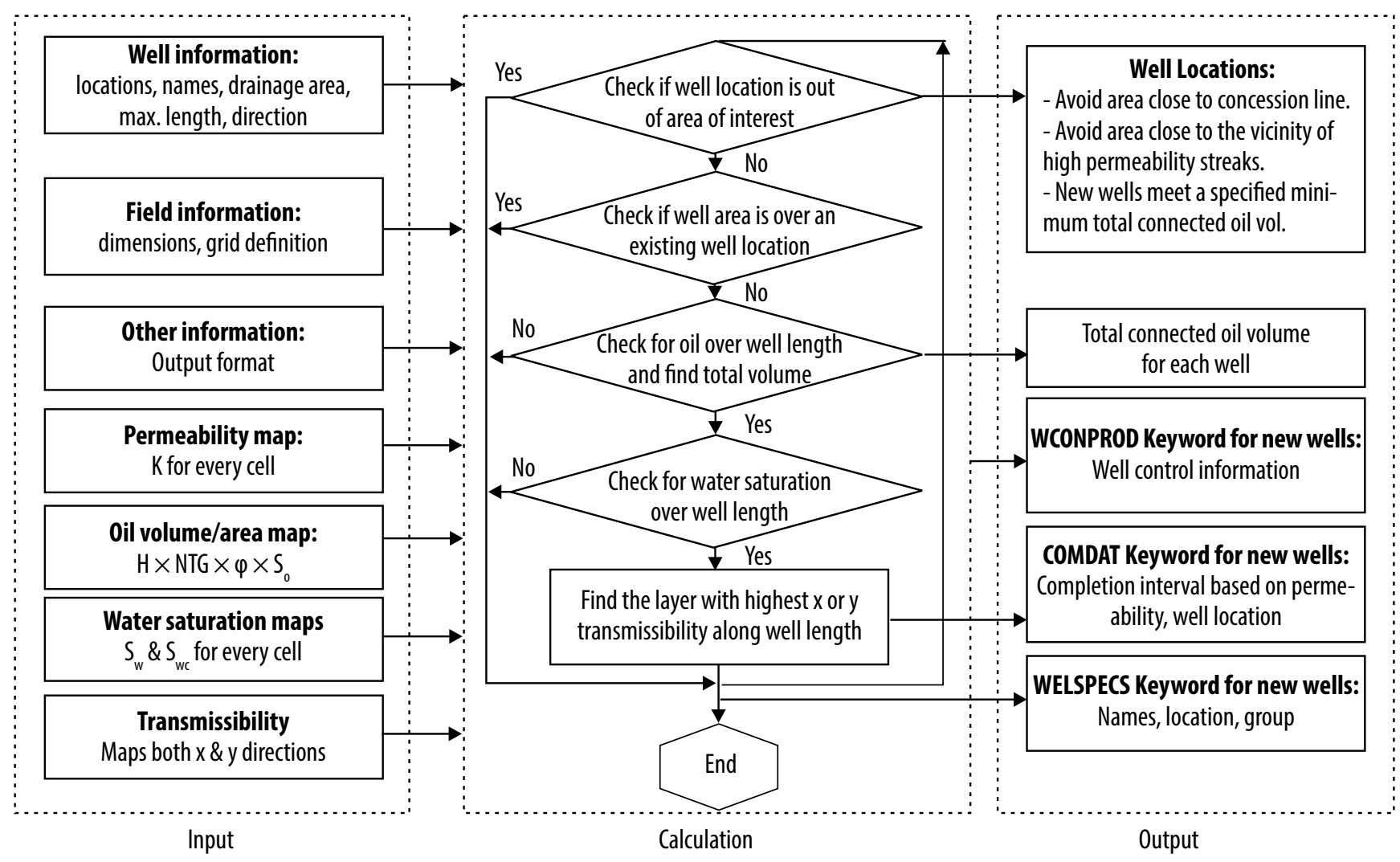

Figure 1. Workflow diagram for the well planning programme.

(vector NUM). The lowest well is assigned 1, and the highest well has the highest number.

The total number of wells is divided in three sets. Wells from each set are sorted according to their connected oil column index using the same subroutine. The keyword for drilling queue is added in the well control output file, and well names are added in the following order:

- Lower wells, sorted by decreasing oil column index;

- Medium wells, sorted by decreasing oil column index;

- Upper wells, sorted by decreasing oil column index.

The output files are then ready to be included in the simulator data file to make a forecast run. The method to make the best use of this programme consists of running it using different well spacing and orientations, then including the files from those alternatives in different data files and making the respective forecast runs. The opening queue can be modified by hand using the knowledge of facts outside the scope of this work.

Even after the wells have been selected through several filters, the result of the simulation runs will point out some wells with non-significant production that can be further discarded.
The auxiliary file screenoutput.txt is used to analyse the internal flow of the programme and can later be omitted. Figure 1 shows a workflow diagram of the programme.

\section{Application example}

\subsection{Problem statement}

Reservoir E-1 is a sample exercise represented by a 31 $\times 21 \times 17$ cells numerical model in the reservoir simulation software. The average horizontal block dimension is $120 \times 120 \mathrm{~m}$. There are multiple small sealing faults and shale zones scattered in the reservoir. Water aquifers are at the bottom and the edge of the reservoir. High-permeability streaks are also present in the reservoir with a permeability magnitude of $30 \mathrm{D}$. There are five existing wells, both vertical and horizontal. The goal is to plan as many horizontal wells as needed to effectively produce the field to its maximum potential. The number of horizontal wells required could be up to 300 depending on the production need and well configuration. Manually placing this large number of wells is a tedious task and may involve many human errors. It becomes impossible under a certain time constraint and when a sensitivity study (considering different well plan scenarios) is required. Thus, the method described above was used for planning new horizontal 
wells in the field. The following criteria were considered for this example:

- New wells are placed 100 m away from the high-permeability streaks;

- Only wells that meet the minimum total connected oil volume are output;

- New wells are placed in the layers with the highest transmissibility along the well length and above the water level, which is defined by input data;

- Either wells along the X orY direction can be considered;

- Output can be imported to the simulation software in form of the keywords for well specification, well production control, well completion, and drilling queue.

\subsection{Results}

Figure 2 shows the E-1 new wells on a schematic area map.

A useful tool in the analysis of this run is the plot of oil cumulative per well (Figure 3).

Note that from the more than 400 wells located, half of them have a non-significant cumulative and can be discarded. A criterion for discarding a well can be producing less than $3 \%$ of total field increment in cumulative.

Figure 4 shows the new wells on and oil column index map. All new wells are at good distance $(100 \mathrm{~m})$ away from the highpermeability streaks. Figure 5 is a cross section of an oil saturation map showing the completion interval of three wells. The wells are well above the high water saturation level. It should be noted that the programme also compared the transmissibilities of the layers above the water level and completed the well in the layer with the highest transmissibility.

\section{Other cases}

\subsection{Horizontal well in the $Y$ direction}

In this case, the azimuth of the well

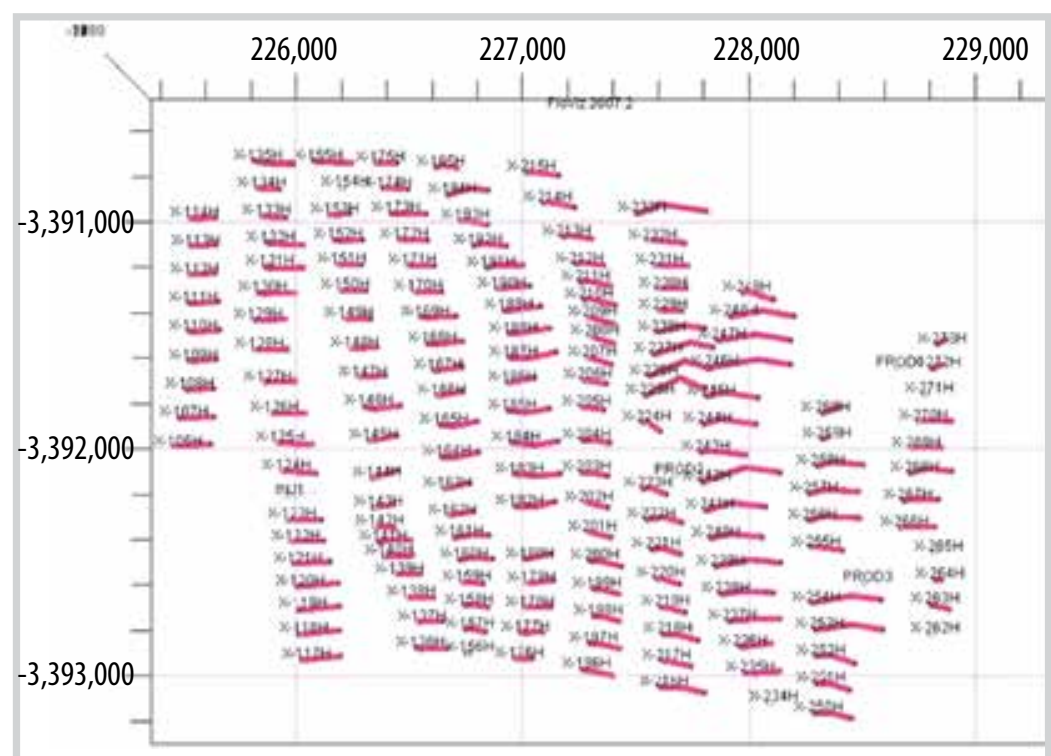

Figure 2. Area map showing the new well locations in reservoir E-1.

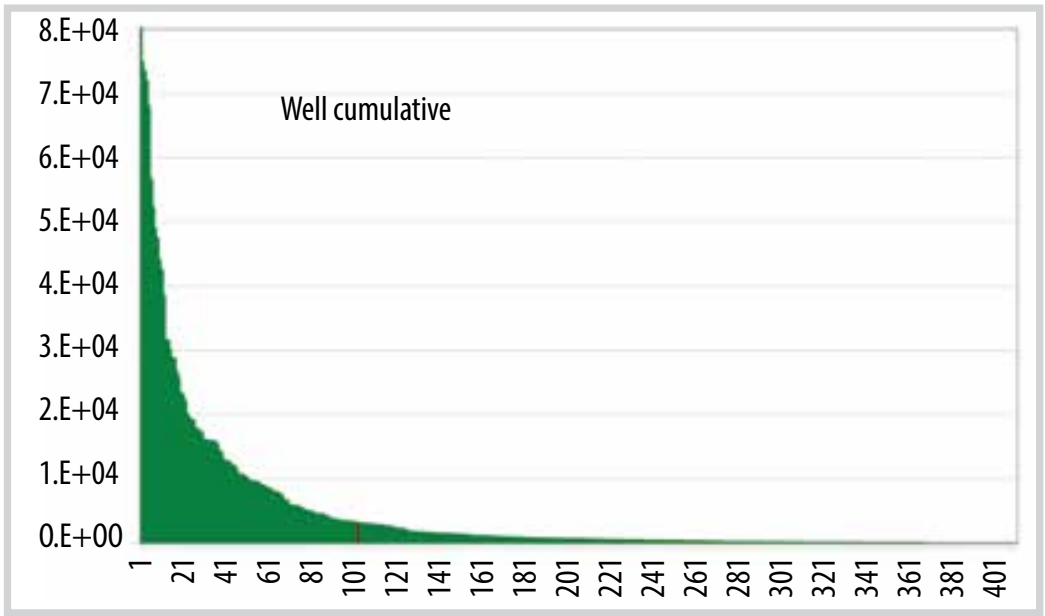

Figure 3. Oil cumulative forecasted for new wells in regular pattern.

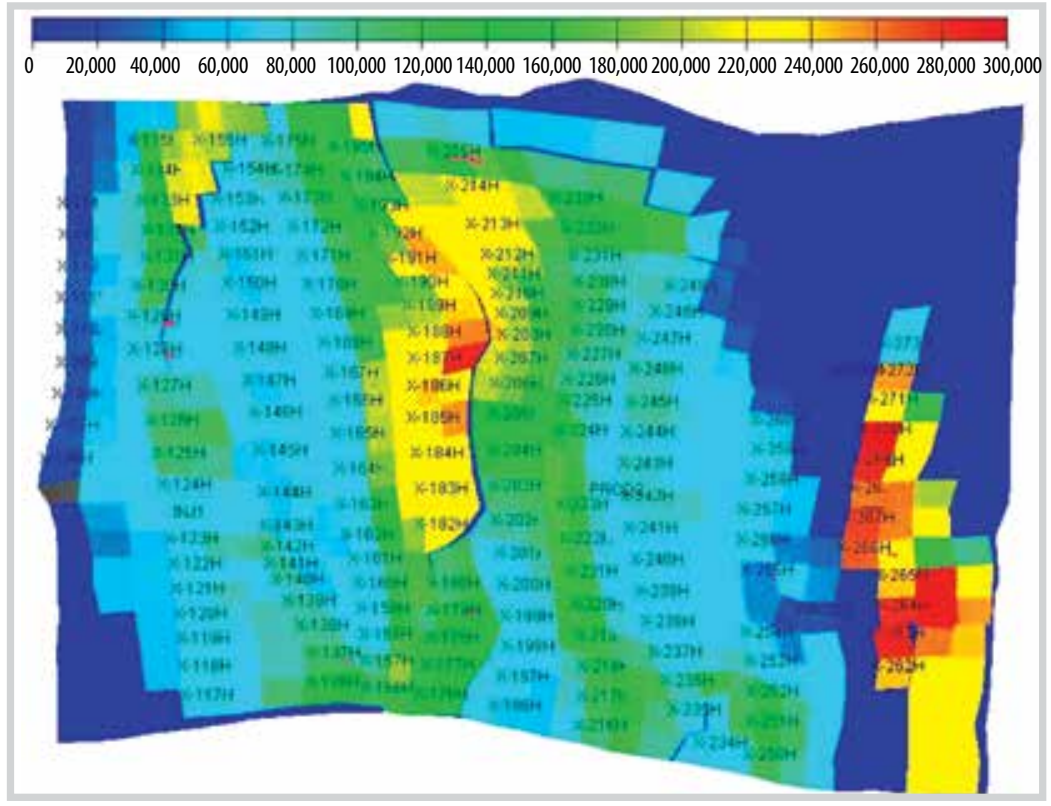

Figure 4. Oil column index map showing the new well locations in reservoir E-1. 


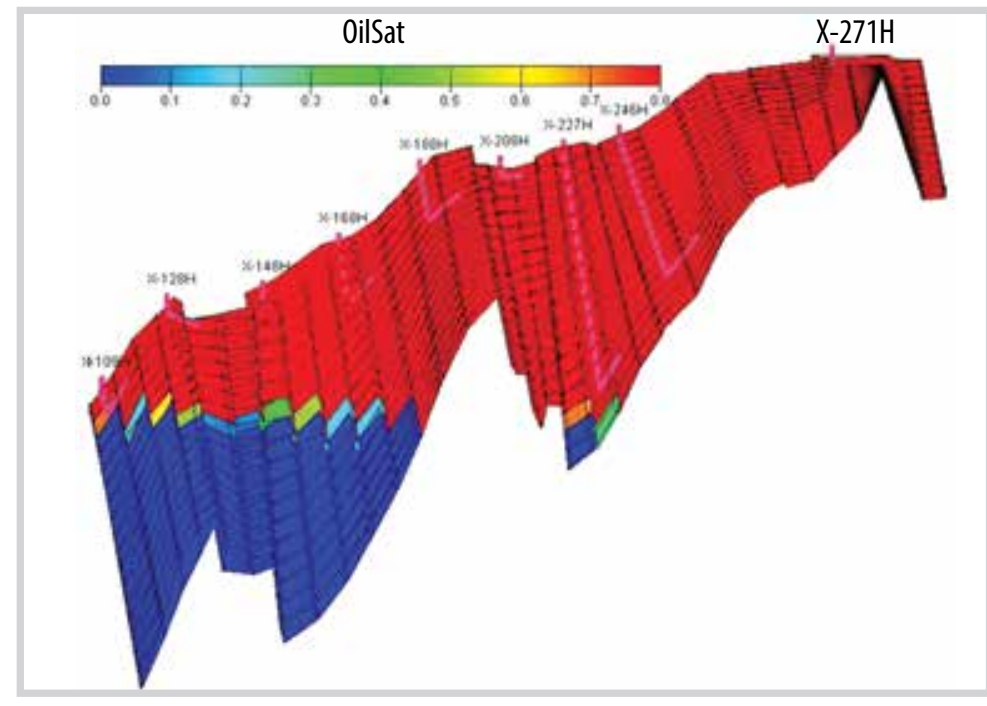

Figure 5. Cross section of oil saturation map showing the new wells for reservoir E-1.

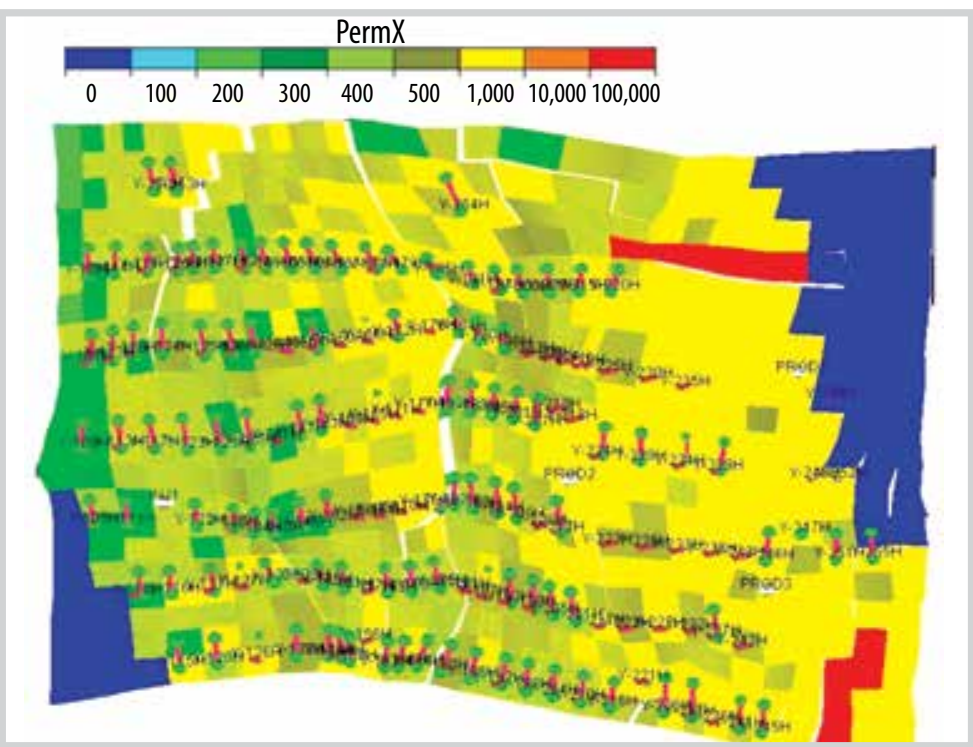

Figure 6. New horizontal well in the $Y$ direction for reservoir $E-1$.

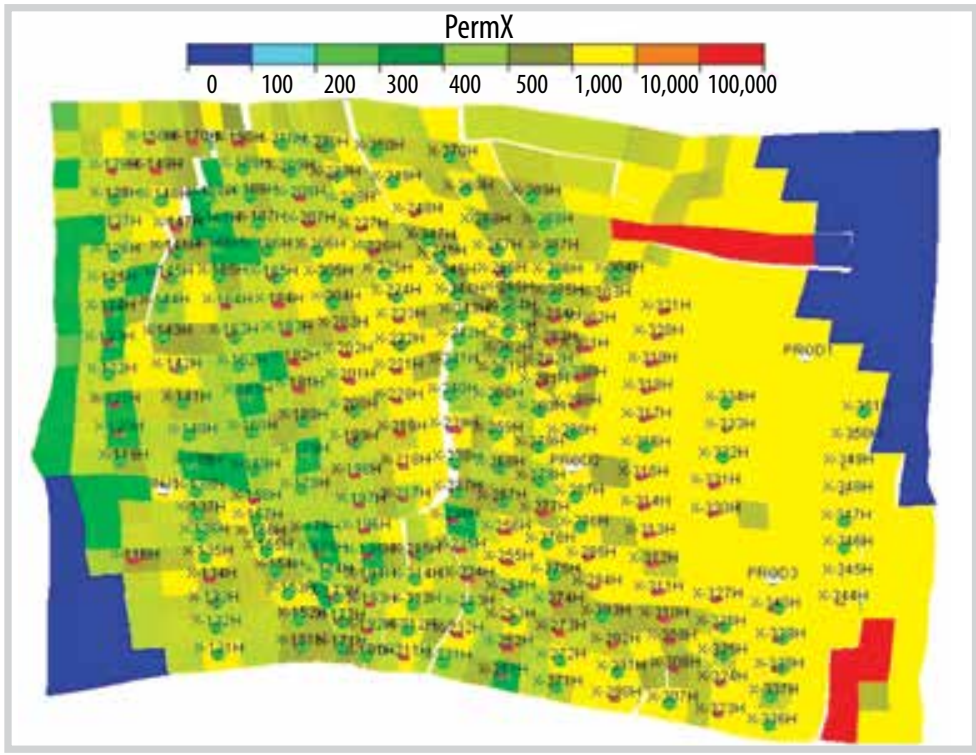

Figure 7. Permeability map showing the new wells with shorter length in reservoir E-1. is in the $Y$ direction instead of the $X$ direction. The dimensions of the well drainage area were switched (the edge along the $X$ axis is now along the $Y$ axis and vice versa). Figure 6 shows the resultant new wells oriented along the $Y$ directions in a permeability map. Similar to the case of new well in an $\mathrm{X}$ direction, all criteria were also met in this case.

\subsection{Shorter well length}

In this case, the maximum length of the new wells was set to be shorter than previous cases (reduced to $350 \mathrm{ft}$ from $700 \mathrm{ft}$ ). The drainage area was reduced, and the new wells were closer to one another. Figure 7 shows the permeability map with the resulting wells.

\section{Assumptions and limitations}

The workflow described above is valid in the following assumptions and limitations:

- The cost of drilling wells has secondary incidence in the economy of the project. This is valid in present circumstances in many locations, as clients require placing a large number of wells to get high production even when interference will occur;

- The cells in the area where the wells will be planned are square and have homogeneous size;

- The thickness of all layers is similar in this area;

- The average thickness of two layers is a valid standoff from water;

- The horizontal transmissibility is defining the well's productivity index;

- The wells will follow the layers even if the layer has high dip;

- Mobile water saturation increases monotonically with depth;

- Each well will be able to drain all the volume contained in its drainage area, meaning horizontal barriers are irrelevant.

The theoretical calculation of the productivity index of a horizontal well is a complex problem which some authors (Hazlett and Babu [1], 
Babu and Odeh [2]) have attempted to solve. The found correlations have given poor matches with the model results, so the transmissibility was adopted as a criterion instead of productivity index for the sake of simplicity.

\section{Improvements and generalisation}

The present version of the programme was created to meet the requirements of developing a specific field, but it can be applied to any case for which the given assumptions are valid. It still can be easily adapted for other cases.

However, there are some improvements, clearly foreseen while developing the programme, which are being worked out:

- Using a standoff given in depth, rather than a number of layers;

- Calculating the productivity index of the well using the correlation of Babu and Odeh [2] or similar;

- Using productivity index as a criterion for qualifying the wells rather than transmissibility;

- Using productivity index to rank the wells in the opening queue;

- Using all the volume of the well drainage area as a criterion for qualifying wells (assuming that the vertical barriers along the axis of the well are not continuous or significant);

- Giving an alternative drilling order for the wells based on the number of available rigs and a logical path of the rigs along the field;

- Detaching the module for defining the highpermeability channels as a separate programme;

- Giving a special treatment to faults, as they can be considered obstacles for drilling.

A further step will be to generalise the programme to cover cases where the above assumptions are not valid:

- Using geometric coordinates $X, Y, Z$ rather than grid coordinates I, J, K;

- Defining the wells as horizontal even in high dip layers (thus not following the layer);

- Using any orientation for the wells besides those parallel to the $\mathrm{X}$ or $\mathrm{Y}$ axis;

- Input from map files instead of simulator files;

- Output in geometric co-ordinates $X, Y, Z$ besides co-ordinates I, J, K.

\section{Conclusions}

The new method helps to save significant working hours and avoid human errors, especially when many development scenarios need to be considered. A large reservoir with hundreds of wells may have infinite possible solutions; this approach has the aim of giving the most significant. A horizontal well planning module would be a useful tool for commercial simulation software to ease engineers' tasks.

\section{Nomenclature}

$\mathrm{H}_{\mathrm{u}}$ : Net thickness

$\mathrm{S}_{\mathrm{o}}$ : Oil saturation

$\mathrm{S}_{\text {wat }}$ : Water saturation array

$\mathrm{S}_{\text {wcr }}$ : Critical water saturation array

Ф: Porosity

\section{References}

[1] Randy D. Hazlett and D. Krishna Babu, "Optimal well placement in Heterogeneous reservoirs through semi-analytic modeling", SPE Journal, Vol. 10, No. 3, pp. 286 - 296, 2005. DOI: 10.2118/84281-PA.

[2] D.K. Babu and A.S. Odeh, "Productivity of a horizontal well appendices A and B", SPE Annual Technical Conference and Exhibition, Houston, Texas, 2 - 5 October 1988. DOI: 10.2118/18334-MS.

[3] A. Stan Cullick, Keshav Narayanan, and Sheldon Burt Gorell, "Optimal field development planning of well locations with reservoir uncertainty", SPEAnnual Technical Conference and Exhibition, Dallas, Texas, 9 - 12 October 2005. DOI: 10.2118/96986-MS.

[4] Alvaro Cottini Loureiro and Mariela G. Araujo Fresky, "Optimized well location by combination of multiple-realization approach and quality map methods", SPE Annual Technical Conference and Exhibition, Dallas, Texas, 9 - 12 October 2005. DOI: 10.2118/95413-MS.

\section{SI Metric Conversion Factors}

bbl $\times 1.589873 \times 10^{-1}=\mathrm{m}^{3}$

$\mathrm{ft} \times 3.048 \times 10^{-1} \mathrm{t}=\mathrm{m}$

$\mathrm{ft}^{3} \times 2.831685 \times 10^{-2}=\mathrm{m}^{3}$

Stbo/Acre $\times 25451.2=1 \mathrm{~m}$

† Conversion factor is exact 


\section{APPENDIX}

Programme Code

PROGRAM WellsNew7

DIMENSION IPO $(:,:), \operatorname{PERM}(:,:,:)$, STBA

$(:,:), \operatorname{SWC}(:,:,:), \operatorname{SW09}(:,:,:)$

DIMENSION DSW $(:,:,:), \operatorname{TRAN}(:,:,:), \mathrm{CH}$ $\operatorname{ANL}(:,:), \operatorname{IPO} 2(:,:)$

DIMENSION $\operatorname{LIMJL}(:), \operatorname{LIMJM}(:)$

DIMENSION ZCORN(:)

DIMENSION ZM(640), TRM(640), OIP(640)

CHARACTER WEL $\star 2$, COMPLET $* 64, \mathrm{GRU} * 5, \mathrm{SPEC} * 17$, CONPROD $* 64$

INTEGER LC8(8), NE(640), NUM(640)

$\mathrm{N}=1$

OPEN $(1$, FILE='Perm.txt ' , ERR=7 $)$

$\mathrm{N}=2$

OPEN $(2$, FILE = 'welinpu.txt ', ERR=7 $)$

$\mathrm{N}=3$

OPEN $(3$, FILE = ' compnew7.txt ', ERR=7)

PRINT *,N

$\operatorname{WRITE}(10, *, \operatorname{ERR}=8) \mathrm{N}$

$\mathrm{N}=4$

OPEN $(4$, FILE= 'stboacre.inc', ERR=7)

PRINT *, N

$\operatorname{WRITE}(10, *, \operatorname{ERR}=8) \mathrm{N}$

$\mathrm{N}=5$

OPEN $(5$, FILE = 'wspecnew7.txt ' , ERR=7)

PRINT *,N

$\operatorname{WRITE}(10, *, \operatorname{ERR}=8) \mathrm{N}$

$\mathrm{N}=7$

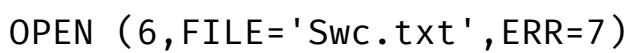

PRINT *,N

$\mathrm{N}=8$

OPEN $(7$, FILE = 'Sw09.txt' , ERR=7)

PRINT *,N

$N=9$
OPEN $(8$, FILE='tran.txt ', ERR=7 $)$

PRINT *,N

$\mathrm{N}=10$

OPEN $(9$, FILE = 'wconprod7.txt ' , ERR=7)

PRINT *,N

$\mathrm{N}=11$

OPEN (10,FILE='screenoutput. txt ' , ERR=7)

PRINT *, N

$\mathrm{N}=12$

$\operatorname{OPEN}(11$, FILE='zcorn.txt', ERR=7)

* Dimensions of grid must be in input file wel.txt. First line box.

$\operatorname{READ}(2, *, \operatorname{END}=8, \mathrm{ERR}=7) \mathrm{IM}, \mathrm{JM}, \mathrm{KM}$

PRINT *, IM, JM, KM

$\operatorname{WRITE}(10, *, E R R=8) I M, J M, K M$

$\operatorname{READ}(2,12, \mathrm{END}=8, \mathrm{ERR}=7) \quad \operatorname{COMPLET}$

PRINT *, COMPLET

$\operatorname{WRITE}(10, *, \mathrm{ERR}=8)$ COMPLET

$\operatorname{READ}(2,12, \mathrm{END}=8, \mathrm{ERR}=7) \quad \operatorname{CONPROD}$

PRINT *, CONPROD

$\operatorname{WRITE}(10, *, \mathrm{ERR}=8)$ COMPLET

$\operatorname{READ}(2, *, E N D=8, E R R=7) \quad \operatorname{IPMIN}, \operatorname{IPMX}, J P$ MIN , JPMX, NCRI , NCR J , LEN , NOR

PRINT *, IPMIN, IPMX, JPMIN, JPMX, NCRI, NCRJ , LEN , NOR

$\operatorname{WRITE}(10, *, E R R=8) \operatorname{IPMIN}, \operatorname{IPMX}$, JPMIN , J PMX, NCRI , NCRJ , LEN , NOR

$\operatorname{READ}(2, *, \operatorname{END}=8, \mathrm{ERR}=7) \quad \mathrm{WEL}, \mathrm{NEW}, \mathrm{KMAX}$

PRINT *, WEL, NEW

$\operatorname{WRITE}(10, *, \operatorname{ERR}=8) \mathrm{WEL}, \mathrm{NEW}$

$\operatorname{READ}(2,28, \mathrm{END}=8, \mathrm{ERR}=7) \quad \mathrm{GRU}, \mathrm{SPEC}$

PRINT *, GRU, SPEC

$\operatorname{WRITE}(10, *, \mathrm{ERR}=8) \mathrm{GRU}, \mathrm{SPEC}$

PRINT *, 'FILE WEL.TXT READ'

$\operatorname{WRITE}(10, *, E R R=8)$ ' FILE WEL.TXT READ ' 
* Define position of horizontal well of length LEN in pattern NCRIxNCRJ

* Orientation of horizontal well $X$ : $\mathrm{NOR}=0 ; \mathrm{Y}: \mathrm{NOR}=1$

* Co-ordinates of the well

$I W=(N C R I-L E N *(1-N O R)) / 2$

$J W=(N C R J-L E N * N O R) / 2$

* Co-ordiantes of the well + Lenghth - 1

$I W F=I W+(L E N-1) *(1-N O R)$

$J W F=J W+(L E N-1) * N O R$

PRINT *, IW, IWF, JW, JWF

ALLOCATE ( IPO (IM, JM), STAT=MALLOC)

IF(MALLOC.NE.0) PRINT *, 'allocation error in IPO'

ALLOCATE ( IP02 ( IM, JM), STAT=MALLOC)

IF(MALLOC.NE.0) PRINT *, 'allocation error in IP02'

ALLOCATE (STBA( IM, JM), STAT=MALLOC)

IF(MALLOC.NE.0) PRINT *, 'allocation error in STBA'

ALLOCATE

(PERM( IM, JM, KM), STAT=MALLOC)

IF(MALLOC.NE.0) PRINT *, 'allocation error in PERM'

ALLOCATE ( SWC ( IM, JM, KM), STAT=MALLOC)

IF(MALLOC.NE.0) PRINT *, 'allocation error in SWC'

\section{ALLOCATE}

(SW09 ( IM, JM, KM), STAT=MALLOC)

IF(MALLOC.NE.0) PRINT *, 'allocation error in SW09'

ALLOCATE (DSW( IM, JM, KM), STAT=MALLOC)

IF(MALLOC.NE.0) PRINT *, 'allocation error in DSW'

ALLOCATE

(TRAN ( IM, JM, KM), STAT =MALLOC)

IF(MALLOC.NE.0) PRINT *, 'allocation error in TRAN'

ALLOCATE (CHANL ( IM, JM), STAT=MALLOC)

IF(MALLOC.NE.0) PRINT *, 'allocation error in CHANL'

ALLOCATE ( LIMJL ( IPMX), STAT=MALLOC)

IF(MALLOC.NE.0) PRINT *, 'allocation error in LIMJL'

ALLOCATE ( LIMJM( IPMX), STAT=MALLOC)

IF(MALLOC.NE.0) PRINT *, 'allocation error in LIMJM'

$I M 1=I M+1$

$J M 1=J M+1$

$M Z C O R N=8 * I M * J M * K M$

ALLOCATE ( ZCORN (MZCORN), STAT=MALLOC)

IF(MALLOC.NE.0) PRINT *, ' could not allocate ZCORN'

$\operatorname{READ}(11, *, \operatorname{END}=8, \operatorname{ERR}=7) \quad \mathrm{ZCORN}$

DO I=IPMIN, IPMX

$\operatorname{READ}(2, *, E N D=8, E R R=7)$

LI , LIMJL( LI ), LIMJM( LI)

END DO

DO $\mathrm{J}=1, \mathrm{JM}$

DO $I=1, I M$

$\operatorname{CHANL}(I, J)=0$

$\operatorname{IPO}(I, J)=0$

$\operatorname{IP02}(\mathrm{I}, \mathrm{J})=0$

END DO

END DO

* Reads PERMsity array in input

PERM.txt. First line PERM

* $\operatorname{READ}(1, *, E N D=8, E R R=7) \quad A B C$

* PRINT *,ABC

$\operatorname{READ}(1, *, \operatorname{END}=8, \mathrm{ERR}=7) \operatorname{PERM}$

PRINT *, N

$\operatorname{WRITE}(10, *, \operatorname{ERR}=8) \mathrm{N}$

PRINT *, $\operatorname{PERM}(6,6,8)$

$\mathrm{N}=6$ 


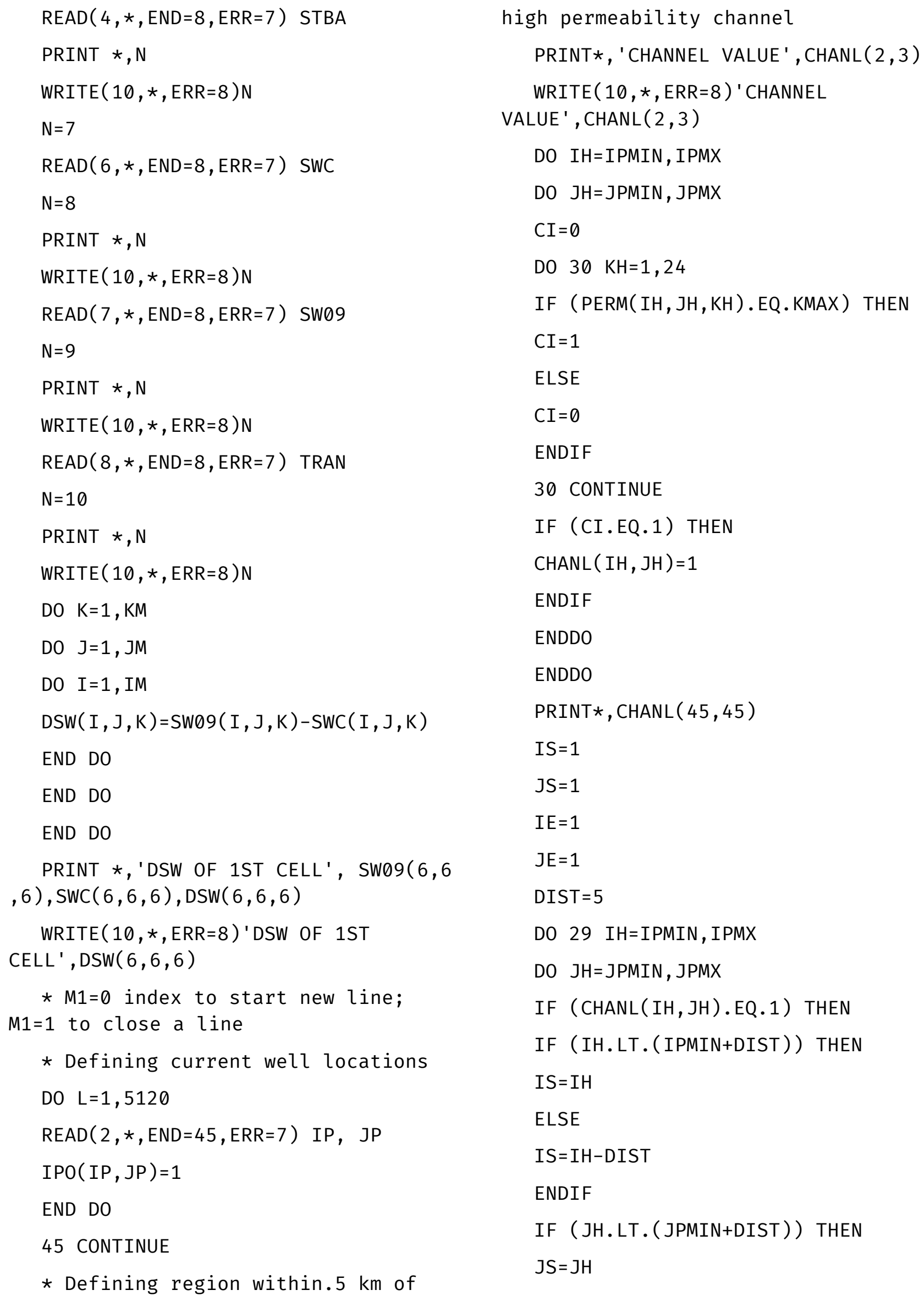

high permeability channel PRINT*, 'CHANNEL VALUE' $\operatorname{CHANL}(2,3)$ $\operatorname{WRITE}(10, *, \mathrm{ERR}=8)$ ' CHANNEL VALUE ' , $\operatorname{CHANL}(2,3)$

DO IH=IPMIN , IPMX

DO JH=JPMIN , JPMX

$\mathrm{CI}=0$

DO $30 \mathrm{KH}=1,24$

IF (PERM( IH, JH, KH).EQ. KMAX) THEN

$\mathrm{CI}=1$

ELSE

$\mathrm{CI}=0$

ENDIF

30 CONTINUE

IF (CI.EQ.1) THEN

$\operatorname{CHANL}(\mathrm{IH}, \mathrm{JH})=1$

ENDIF

ENDDO

ENDDO

PRINT*, CHANL $(45,45)$

IS $=1$

$\mathrm{JS}=1$

$\mathrm{IE}=1$

$\mathrm{JE}=1$

DIST $=5$

DO 29 IH=IPMIN, IPMX

DO JH=JPMIN, JPMX

IF (CHANL ( IH, JH).EQ.1) THEN

IF (IH.LT. (IPMIN+DIST)) THEN

IS $=$ IH

ELSE

IS $=$ IH-DIST

ENDIF

IF (JH.LT. (JPMIN+DIST)) THEN $\mathrm{JS}=\mathrm{JH}$ 


\section{ELSE}

$\mathrm{JS}=\mathrm{JH}-\mathrm{DIST}$

ENDIF

IF ( IH.GT. (IPMX-DIST)) THEN

$I E=I H$

ELSE

$I E=I H+D I S T$

ENDIF

IF ( JH.GT. (JPMX-DIST)) THEN

$\mathrm{JE}=\mathrm{JH}$

ELSE

$\mathrm{JE}=\mathrm{JH}+\mathrm{DIST}$

ENDIF

DO $I=I S, I E$

DO J=JS, JE

$\operatorname{IP02}(I, J)=1$

ENDDO

ENDDO

ENDIF

ENDDO

29 CONTINUE

DO $I=1, I M$

DO $\mathrm{J}=1, \mathrm{JM}$

$\operatorname{WRITE}(10, *, \operatorname{ERR}=8) \mathrm{I}, \mathrm{J}, \operatorname{CHANL}(\mathrm{I}, \mathrm{J})$

ENDDO

ENDDO

* DEFining NEW WELL LOCATiOnS

$N W C=0$

DO I=IPMIN , IPMX-NCRI, NCRI

DO J=LIMJL ( I ), LIMJM(I )-NCRJ, NCRJ

$M 1=0$

$\mathrm{K} 1=0$

$M A R=0$

$\mathrm{OP}=0$

$\mathrm{I} 10=\mathrm{I}+\mathrm{NCRI}-1$
$\mathrm{J} 5=\mathrm{J}+\mathrm{NCR} \mathrm{J}-1$

$Z M(N W C+1)=0$

* VERIFIES IF LOCATION IS OVER EXISTING WELL

D0 $32 \mathrm{IN}=\mathrm{I}, \mathrm{I} 10$

DO $36 \mathrm{JN}=\mathrm{J}, \mathrm{J} 5$

$\operatorname{IF}(\operatorname{IPO}(I N, J N)$. EQ.1) THEN

GO TO 50

ENDIF

36 CONTINUE

32 CONTINUE

* SUMmATION OF OIL VOLUME OVER WELL LENGTH

38 D0 $40 \mathrm{IN}=\mathrm{I}+\mathrm{IW}, \mathrm{I}+\mathrm{IWF}$

DO $\mathrm{JN}=\mathrm{J}+\mathrm{JW}, \mathrm{J}+\mathrm{JWF}$

$\mathrm{OP}=\mathrm{OP}+\mathrm{STBA}(\mathrm{IN}, \mathrm{JN})$

END DO

40 CONTINUE

IF(OP.EQ.0) THEN

GO TO 50

ENDIF

$N E W=N E W+1$

DO 132 IN=I, I10

DO $136 \mathrm{JN}=\mathrm{J}, \mathrm{J} 5$

$\operatorname{IF}(\operatorname{IPO2}(\mathrm{IN}, \mathrm{JN})$. EQ.1) THEN

GO TO 50

ENDIF

136 CONTINUE

132 CONTINUE

* FINDING THE LOWEST LAYER ABOVE LAYER WITH MAX. SW DIFFERENCE

$\mathrm{K} 2=\mathrm{KM}$

$K D=K M$

DSWMAX $=0.15$

DO IN $=I+I W, I+I W F$

DO $41 \mathrm{JN}=\mathrm{J}+\mathrm{JW}, \mathrm{J}+\mathrm{JWF}$ 


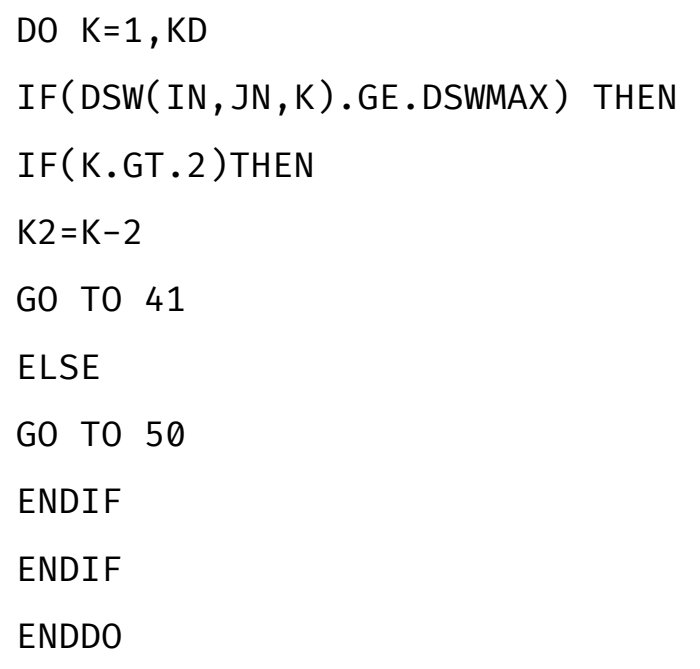

\section{CONTINUE}

ENDDO

* Finding the LAYER With mAX. TRANS.

$\mathrm{K} 3=\mathrm{K} 2$

TRANMAX $=0$

DO $26 \mathrm{~K}=\mathrm{K} 2,1,-1$

TRANTOT $=0$

DO $I N=I+I W, I+I W F$

DO $J N=J+J W, J+J W F$

TRANTOT $=$ TRAN $(I N$, JN , K $)+$ TRANTOT

ENDDO

ENDDO

IF(TRANTOT . GT . TRANMAX) THEN

TRANMAX $=$ TRANTOT

$\mathrm{K} 3=\mathrm{K}$

* PRINT *, ' TRANMAX ' , TRANMAX

ENDIF

26 CONTINUE

*WRITING OUTPUT TO FILES

IF(OP.GT.50000) THEN

TRANCOMP $=0$

SWCOMP $=0$

DO $22 \mathrm{IN}=\mathrm{I}+\mathrm{IW}, \mathrm{I}+\mathrm{IWF}$

DO $25 \mathrm{JN}=\mathrm{J}+\mathrm{JW}, \mathrm{J}+\mathrm{JWF}$

$\operatorname{IF}(\operatorname{STBA}(I N, J N) . G T .0)$ THEN

IF (TRANMAX.GT. $\oslash)$ THEN

IF ( TRAN( IN, JN, K3 ).GT. 0 ) THEN

TRANCOMP $=$ TRAN $(\mathrm{IN}, \mathrm{JN}, \mathrm{K} 3)$

SWCOMP $=S W 09($ IN , JN , K3 )

WRITE $(3,16, E R R=8) W E L, N E W$, ' $H$ ' , IN , JN, $\mathrm{K} 3, \mathrm{~K} 3$, COMPLET, TRANCOMP, SWCOMP

M1 =1

ENDIF

ENDIF

ENDIF

CALL ZMED( I , J, K3 , IM, JM, LC8 $)$

$\mathrm{SZ}=0$

DO $L=1,8$

$M=L C 8(L)$

$\mathrm{SZ}=\mathrm{SZ}+\mathrm{ZCORN}(\mathrm{M})$

END DO

$\mathrm{SZ}=\mathrm{SZ} / 8$

$\operatorname{IF}(S Z \cdot G T \cdot Z M(N W C+1))$ THEN

$\mathrm{ZM}(\mathrm{NWC}+1)=\mathrm{SZ}$

ENDIF

25 CONTINUE

22 CONTINUE

IF (M1.EQ.1) THEN

WRITE $(5,20$, ERR =8 $) W E L, N E W, '$ ' ' , GRU, I+ IW, J+ JW, SPEC, OP, TRANMAX

WRITE $(9,13$, ERR $=8) W E L, N E W, '{ }^{\prime}$ ' , CONPRO D , OP , TRANMAX, ZM( NWC +1)

$\mathrm{NWC}=\mathrm{NWC}+1$

$N E(N W C)=N E W$

$\operatorname{NUM}($ NWC $)=N W C$

$\operatorname{OIP}(N W C)=O P$

$\operatorname{TRM}($ NWC $)=$ TRANMAX

ENDIF

ENDIF

$\mathrm{N}=9$

50 CONTINUE 
END DO

END DO

$\operatorname{WRITE}(3,16, \operatorname{ERR}=8)$ ' / '

*Well classification by: 1) depth

2) OIP in three sets

$\mathrm{ION}=1$

CALL ORDEM( ZM, NUM, ION, NWC)

$\operatorname{WRITE}(9,16, \operatorname{ERR}=8)^{\prime} / /$

$\operatorname{WRITE}(9, *, \mathrm{ERR}=8)$ ' QDRILL '

$\mathrm{M} 1=\mathrm{NWC} / 3$

* Lower Wells

$\mathrm{ION}=1$

CALL ORDEM(OIP, NUM, ION, M1)

DO L=ION, M1

$N M=N U M(L)$

$\operatorname{WRITE}(9,20, \mathrm{ERR}=8) \mathrm{WEL}, \mathrm{NE}(\mathrm{NM})$, ' $\mathrm{H}$ '

END DO

$\operatorname{WRITE}(9,16, \operatorname{ERR}=8)^{\prime} / /$

$\operatorname{WRITE}(9, *, \operatorname{ERR}=8)$ ' QDRILL '

* Medium Wells

$\mathrm{ION}=\mathrm{M} 1+1$

$M 2=2 \star M 1$

CALL ORDEM(OIP, NUM, ION, M2)

DO L $=I O N, M 2$

$N M=N U M(L)$

$\operatorname{WRITE}(9,13, \operatorname{ERR}=8) \mathrm{WEL}, \operatorname{NE}(\mathrm{NM})$, ' H '

END DO

$\operatorname{WRITE}(9,16, \operatorname{ERR}=8)^{\prime} / /$

$\operatorname{WRITE}(9, *, \operatorname{ERR}=8)$ ' QDRILL '

* Upper Wells

$\mathrm{ION}=\mathrm{M} 2+1$

CALL ORDEM(OIP, NUM, ION, NWC)

DO $L=I O N$, NWC

$N M=N U M(L)$

$\operatorname{WRITE}(9,13, \operatorname{ERR}=8) \mathrm{WEL}, \operatorname{NE}(\mathrm{NM})$, ' H '

END DO
$\operatorname{WRITE}(9,16, \operatorname{ERR}=8)$ ' /'

8 PRINT *, N, 'FIN'

PRINT *, 'TOTAL NO. OF WELL: ', NWC

$\operatorname{WRITE}(10, *, \operatorname{ERR}=8)$ ' TOTAL NO. OF WELL: ' , NWC

$\operatorname{WRITE}(10, *, \operatorname{ERR}=8) \mathrm{N}$, ' FIN '

STOP

7 PRINT *, 'File not opened'

$\operatorname{WRITE}(10, *, \operatorname{ERR}=8)$ 'File not opened'

16 FORMAT( $A 2, I 3, A 1$,

4I6, 2XA64,F10.3,F10.4)

$28 \operatorname{FORMAT}(\mathrm{A} 5, \mathrm{~A} 17)$

$20 \operatorname{FORMAT}(\mathrm{A} 2, \mathrm{I} 3, \mathrm{~A} 1,2 \mathrm{XA5}, 2 \mathrm{I} 6,2 \mathrm{XA17}$, ' $/$, F10.0, F10.3)

12 FORMAT(A64)

13 FORMAT( $A 2, I 3, A 1$, $A 40, F 10.0, F 10.3, F 10.1)$

5 CLOSE (1)

CLOSE (2)

CLOSE (3)

END

SUBROUTINE ZMED(I0,J0, KO, IMI, JMJ, L8)

INTEGER L8(8)

* For each cell:

* Corner 1 lower i lower j upper k $\mathrm{i}-\mathrm{j}-\mathrm{k}+$

* Corner 2 higher i lower j upper $k$ $i+j-k+$

* Corner 3 lower i higher $j$ upper $k$ i- j+ k+

* Corner 4 higher $i$ higher $j$ upper $\mathrm{k} i+\mathrm{j}-\mathrm{k}+$

* Corner 5 lower i lower j down k i- j-k-

* Corner 6 higher $i$ lower j down $k$ $i+j-k-$

* Corner 7 lower $i$ higher $j$ down $k$ $i-j+k-$ 
* Corner 8 higher i higher j down k $i+j-k-$

\section{J $4=4 * I M I * J M J$}

* to extract $z$ co-ordinates for each corner, from ZCORN array, above convention

$$
\mathrm{L} 8(2)=2 * I 0+4 * I M I *((J 0-
$$

1) $+2 * J M J *(K \theta-1))$

$$
\begin{aligned}
& \mathrm{L} 8(1)=\mathrm{L} 8(2)-1 \\
& \mathrm{~L} 8(4)=2 * \mathrm{I} 0+2 * \mathrm{IMI} *((2 * \mathrm{~J} 0-
\end{aligned}
$$

1) $+4 * J M J *(K \theta-1))$

$$
\begin{aligned}
& \mathrm{L} 8(3)=\mathrm{L} 8(4)-1 \\
& \mathrm{~L} 8(5)=\mathrm{L} 8(1)+\mathrm{IJ} 4 \\
& \mathrm{~L} 8(6)=\mathrm{L} 8(5)+1 \\
& \mathrm{~L} 8(7)=\mathrm{L} 8(3)+\mathrm{IJ} 4 \\
& \mathrm{~L} 8(8)=\mathrm{L} 8(7)+1
\end{aligned}
$$

\section{RETURN}

\section{END}

* SUBROUTINE ORDEM orders a subset of wells through number NPO

* by descending values of vector $Z a$. The subset starts at Juno, ends at LM.

* Vector NPO may initially have the numeral order $(1,2,3, \ldots)$ and is output

* having in the first place the well number having the highest $Z a$, and subsequently

* to the well having the lowest $\mathrm{Za}$

SUBROUTINE ORDEM(ZA, NPO, JUNO, LM)

DIMENSION ZA(640)

\section{INTEGER NPO(640)}

$M L=(L M+J U N O-1) / 2$

DO IA $=$ JUNO, ML

$Z M X=-1 E 32$

$\mathrm{ZMN}=1 \mathrm{E} 32$

DO IB $=I A, L M-I A+J U N O$

$I C=N P O(I B)$
IF ( ZA ( IC ).GT.ZMX) THEN

$Z M X=Z A(I C)$

IMAX $=I B$

ELSE

IF(ZA (IC). LT.ZMN) THEN

$Z M N=Z A(I C)$

$I M I N=I B$

ENDIF

ENDIF

END DO

*In each step places the well having the highest value in subsequent order

* at the beginning, and the well having the lowest value at the end. Places

* are exchanged with wells in those positions.

* Reference is the well number at the original list.

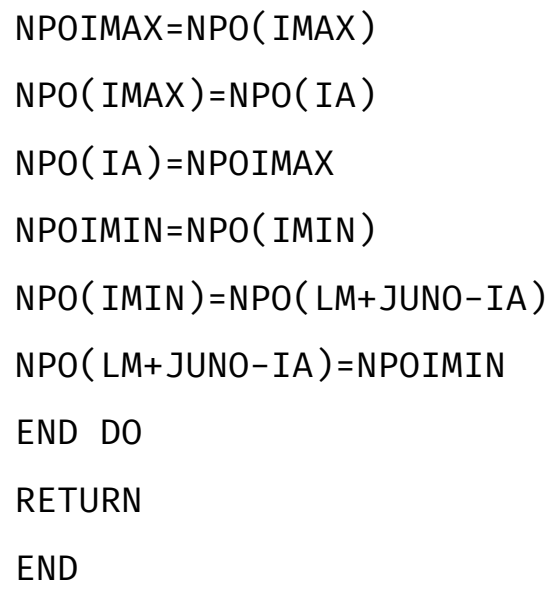

